Esta obra está sob o direito de Licença Creative Commons Atribuição 4.0 Internacional.

\title{
O PROFESSOR COMO PEÇA CHAVE NO PROCESSO DA APRENDIZAGEM ATRAVÉS DO LÚDICO
}

José Silva De Menezes ${ }^{1}$

Adriana De Lima Mendonça ${ }^{2}$

Betijane Soares de Barros ${ }^{3}$

Dílson Cavalcante Tenório ${ }^{4}$

\section{RESUMO}

Este trabalho teve como objetivo analisar o papel do professor como mediador no processo de ensino aprendizagem utilizando o método lúdico. Trata-se de uma revisão sistemática integrativa, baseada na varredura em bases periódicas indexadas. O período de coleta dos dados compreendeu os meses de agosto a março de 2020. Adotaram-se como critério de inclusão: livros, periódicos e trabalhos acadêmicos que contemplavam a ludicidade como ferramenta de aprendizagem, em idioma português. Como critério de exclusão não foram consultados documentos tais como, relatórios e questionários. Dos vinte e sete trabalhos analisados, todos obedeceram aos critérios de inclusão incluída às etapas da presente revisão integrativa. A análise sistemática inferiu na categorização das seguintes abordagens: 1- Ensino aprendizagem e formação inicial docente: Aspectos históricos e de inovação utilizando métodos lúdicos (será que o docente é preparadao na sua formação inicial para aplicar o método lúdico no processo ensino aprendizagem?) 2- Adoção, percepção e relevância do método lúdico na prática docente (Será que o docente aplica o método lúdico na prática? Quais estímulos devem ser adotados para que seja aplicado como uma técnica de ensino aprendizagem). Foi possível concluir que os docentes não se encontram preparados adequadamente para a aplicabilidade do lúdico, porém muitas modificações já ocorreram na questão da formação que no caso deve ser continua. Quanto a aplicabilidade do lúdico em sala de aula, percebe-se que o lúdico é uma das maiores ferramentas para o aprendizado.

Palavras-chave: Lúdico, Escola, Aprendizagem

\footnotetext{
1 jaelson_menezes@hotmail.com

2 adrianapnpd@gmail.com

3 bj-sb@hotmail.com

4 dilsontenorio4@hotmail.com
} 


\section{INTRODUÇÃO}

O debate dos pesquisadores sobre a temática da formação de professores acontece, dentre outros fatores, em virtude das relações em que se insere a problemática, sobretudo, em face do contexto social vigente. Este é influenciado pelas forças neoliberais de políticas educacionais que não atendem às necessidades básicas da educação para que a construção do conhecimento seja bem sucedida no seio da escola.

Uma das formas de repensar a formação dos educadores é introduzir nos cursos de formação uma base e uma estrutura curricular: a formação lúdica. Essa formação levará o futuro educador a conhecer-se como pessoa, saber de suas limitações e possibilidades, para quando este estiver atuando em sala de aula, saberá a importância do jogo e do brinquedo para a vida da criança, do jovem e do adulto.

Contudo, a formação do professor em ludicidade deverá estar pautada em aprendizagens significativas, aproximando as crianças de uma realidade que é a sua, pois essa prática deve estar envolvida com uma intencionalidade, quebrando as barreiras existentes em sala de aula, em que o lúdico muitas vezes é aplicado para completar os espaços vazios do plano diário, assim a brincadeira desenvolverá a formação dos sujeitos, construindo saberes.
$\mathrm{O}$ uso de jogos e brincadeiras em sala de aula pode auxiliar as crianças a explorarem o mundo que as cerca, a construir novos conhecimentos e a motivarse para sua aprendizagem.

É importante lembrar, porém, que esses jogos e brincadeiras devem ser incorporados ao cotidiano escolar, tratados não como uma forma de relaxamento, recreação, onde simplesmente busca-se gastar as energias da criança, mas como uma fonte de conhecimentos, de auxílio a aprendizagem de conteúdo, onde as crianças encontram possibilidades diferenciadas de interpretar e de interagir com as pessoas, objetos, culturas, conhecimentos, emoções, entre outras questões.

A participação do professor é de suma importância nesse processo de desenvolvimento da aprendizagem, pois o professor que irá selecionar as atividades, jogos e brincadeiras que farão parte da aula e que poderão auxiliar na aprendizagem e desenvolvimento das crianças.

\section{METODOLOGIA}

A pesquisa foi elaborada com base no método de revisão integrativa, realizada a partir de dados secundários obtidos de livros, artigos de periódicos, monografias, dissertações e teses indexados nas seguintes bases científicas virtuais, a saber: Periódicos CAPES, Biblioteca Digital 
Brasileira de Teses e Dissertações (BDTD),

SciELO (Scientific Eletronic Library

Online), BVS, Science Direct e JusBrasil.
O detalhamento das etapas da revisão integrativa está descrito no quadro 1.

Quadro 1 - Síntese Metodológica Da Revisão Integrativa.

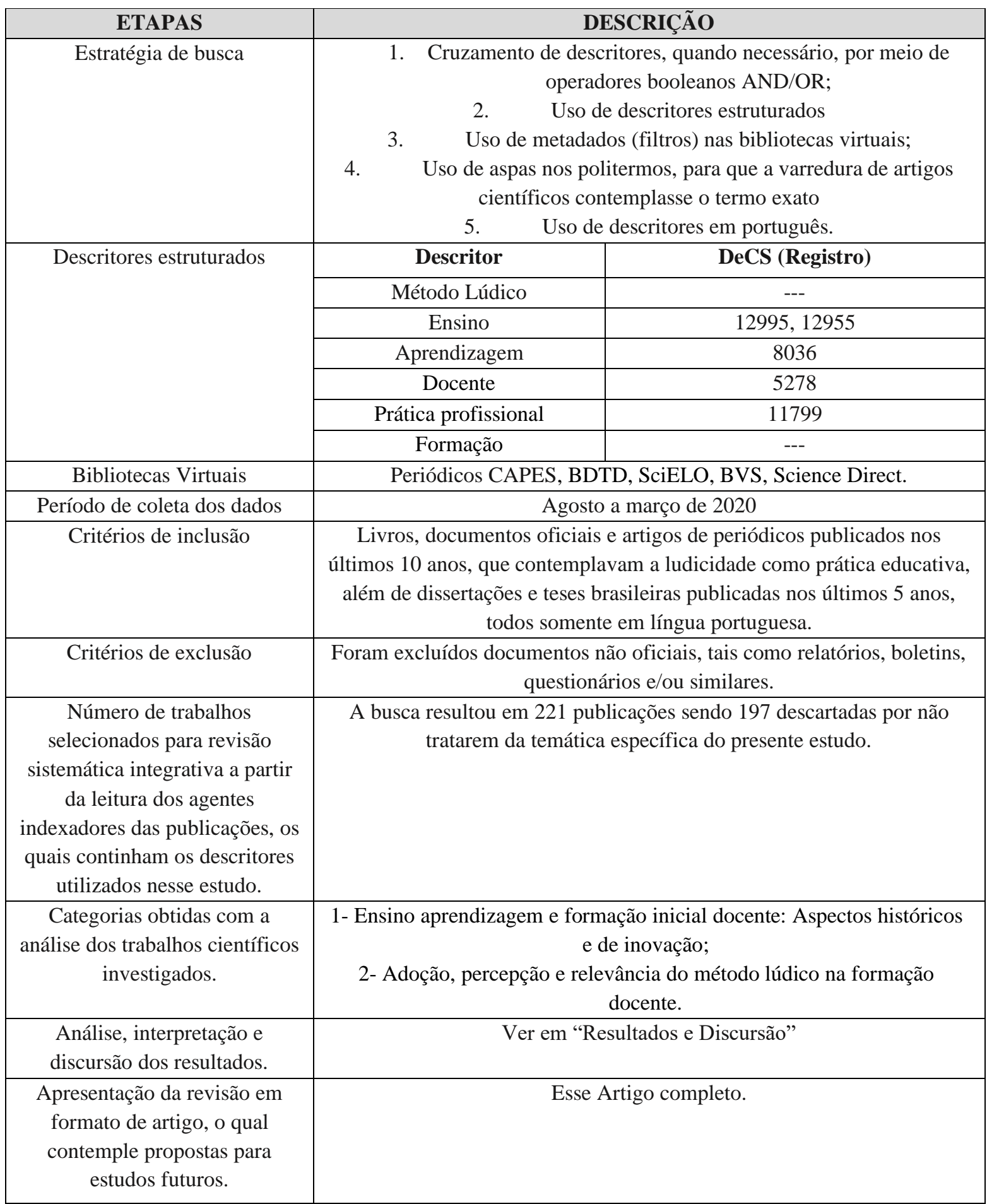

Fonte: Autor, 2020 


\section{RESULTADOS E DISCUSSÃO}

O quadro 2 mostra o quantitativo de publicações obtidas e selecionadas, para o presente estudo, a partir das bases consultadas para a revisão integrativa. Considerando os critérios de inclusão e exclusão e filtros dos descritores (DECs), o presente estudo resultou na análise de 29 publicações, excetuando-se livros, que estão detalhadas de forma sumarizada na tabela 1 .

Quadro 2 - Publicações Utilizadas Para A Revisão Integrativa

\begin{tabular}{|c|c|c|c|c|}
\hline $\begin{array}{c}\text { Estratégia de } \\
\text { busca }\end{array}$ & Bases de dados & $\begin{array}{l}\text { Total de } \\
\text { publicações } \\
\text { sem o filtro }\end{array}$ & $\begin{array}{c}\text { Publicações } \\
\text { disponíveis após } \\
\text { aplicar os filtros }\end{array}$ & $\begin{array}{c}\text { Publicações } \\
\text { aproveitadas na } \\
\text { Revisão Sistemática } \\
\text { Integrativa }\end{array}$ \\
\hline $\begin{array}{l}\text { Docente AND } \\
\text { Lúdico }\end{array}$ & $\begin{array}{c}\text { Periódicos CAPES, } \\
\text { BDTD, SciELO, } \\
\text { BVS, Science } \\
\text { Direct e JusBrasil. }\end{array}$ & $\begin{array}{c}\text { (Docente AND } \\
\text { Lúdico) } \\
\text { BDTD }=193 \text {; } \\
\text { 30; XXXX } \\
\text { Scielo: } 3 ; 1 \\
\text { Science Direct: } \\
\text { 73; 23; XXXX } \\
\text { JusBrasil: } 33 \\
\end{array}$ & 221 & 27 \\
\hline Total & & 32260 & 221 & 27 \\
\hline
\end{tabular}

Fonte: autor, 2020

Quadro 3 - Publicações Chave Para A Revisão Integrativa

\begin{tabular}{|c|c|c|c|c|c|c|}
\hline $\mathbf{N}^{\mathbf{o}}$ & Autor(a) & Tema & $\begin{array}{c}\text { Link da } \\
\text { publicação }\end{array}$ & $\begin{array}{c}\text { Palavras-chave } \\
\text { relacionadas } \\
\text { aos DECs }\end{array}$ & Ano & Conclusão \\
\hline 1 & $\begin{array}{c}\text { Lopes, } \\
\text { Mary } \\
\text { Stela } \\
\text { Sakamot } \\
\text { o }\end{array}$ & $\begin{array}{c}\text { O direito de } \\
\text { aprendizage } \\
\text { m e do } \\
\text { brincar nos } \\
\text { anos iniciais } \\
\text { do ensino } \\
\text { fundamental: } \\
\text { formação } \\
\text { lúdica } \\
\text { docente }\end{array}$ & $\begin{array}{c}\text { http://hdl.ha } \\
\text { ndle.net/114 } \\
49 / 153507\end{array}$ & $\begin{array}{c}\text { Direito à } \\
\text { infância. Direito } \\
\text { de } \\
\text { aprendizagem. } \\
\text { Direito do } \\
\text { brincar. } \\
\text { Ludicidade. } \\
\text { Formação lúdica } \\
\text { docente. }\end{array}$ & 2018 & $\begin{array}{l}\text { Os resultados indicam que as } \\
\text { brincadeiras em sala de aula } \\
\text { não são reconhecidas como } \\
\text { um direito fundamental da } \\
\text { criança; e que professores com } \\
\text { e sem formação lúdica } \\
\text { utilizam, frequentemente, a } \\
\text { ludicidade apenas como } \\
\text { recurso pedagógico para } \\
\text { facilitar a aprendizagem dos } \\
\text { alunos. }\end{array}$ \\
\hline 2 & $\begin{array}{l}\text { Pereira, } \\
\text { Fernanda } \\
\text { Almeida }\end{array}$ & $\begin{array}{l}\text { Ludicidade } \\
\text { na } \\
\text { constituição } \\
\text { da } \\
\text { profissionali } \\
\text { dade de } \\
\text { docentes de } \\
\text { uma creche } \\
\text { universitária: } \\
\text { desafios e } \\
\text { possibilidade } \\
\text { s } \\
\end{array}$ & $\begin{array}{c}\text { http://reposit } \\
\text { orio.ufba.br/ } \\
\text { ri/handle/ri/2 } \\
3985\end{array}$ & $\begin{array}{l}\text { Ludicidade. } \\
\text { Educação } \\
\text { Infantil. } \\
\text { Profissionalidad } \\
\text { e docente. } \\
\text { Saberes } \\
\text { profissionais. }\end{array}$ & 2018 & $\begin{array}{l}\text { constatei que a ludicidade não } \\
\text { se restringe ao ensino, } \\
\text { tampouco ao período da } \\
\text { infância, estando presente de } \\
\text { forma transversal, } \\
\text { constituindo e interligando os } \\
\text { variados saberes docentes que } \\
\text { são construídos a partir da } \\
\text { experiência ao longo dos anos, } \\
\text { do processo de formação } \\
\text { continuada e da ambiência } \\
\text { profissional das professoras }\end{array}$ \\
\hline
\end{tabular}




\begin{tabular}{|c|c|c|c|c|c|c|}
\hline 3 & $\begin{array}{c}\text { Daniella } \\
\text { Caroline } \\
\text { Rodrigue } \\
\text { s Ribeiro } \\
\text { Ferreira }\end{array}$ & $\begin{array}{l}\text { Indústria } \\
\text { cultural, } \\
\text { educação } \\
\text { infantil e } \\
\text { trabalho } \\
\text { docente: } \\
\text { formação e } \\
\text { atuação } \\
\text { lúdica com } \\
\text { crianças }\end{array}$ & $\begin{array}{l}\text { http://www.b } \\
\text { ibliotecadigit } \\
\text { al.uel.br/doc } \\
\text { ument/?code } \\
=\text { vtls000230 } \\
\quad 847\end{array}$ & $\begin{array}{l}\text { Trabalho } \\
\text { doscente; } \\
\text { ludicidade } \\
\text { emacipação. }\end{array}$ & 2019 & $\begin{array}{c}\text { Acredita-se que a pesquisa se } \\
\text { faz relevante para o campo da } \\
\text { educação, pois busca uma } \\
\text { possível compreensão das } \\
\text { práticas pedagógicas e lúdicas } \\
\text { dos professores da escola da } \\
\text { infância e como suas ações } \\
\text { interferem no processo de } \\
\text { ensino e aprendizagem lúdico } \\
\text { de crianças. Como } \\
\text { contribuição, tivemos o intuito } \\
\text { de buscar novos } \\
\text { direcionamentos a respeito das } \\
\text { práticas pedagógicas para } \\
\text { tentarmos ir além da lógica da } \\
\text { indústria cultural e colaborar a } \\
\text { desvanecer os desafios, para } \\
\text { que se torne frequente a } \\
\text { promoção do lúdico no } \\
\text { processo de ensino e } \\
\text { aprendizagem de crianças. }\end{array}$ \\
\hline 4 & $\begin{array}{l}\text { Matheus } \\
\text { Rego } \\
\text { Silveira }\end{array}$ & $\begin{array}{c}\text { Concepções } \\
\text { e práticas } \\
\text { docentes } \\
\text { sobre o } \\
\text { brincar em } \\
\text { sala de aula } \\
\text { no primeiro } \\
\text { ano do } \\
\text { Ensino } \\
\text { Fundamental }\end{array}$ & $\begin{array}{c}\text { http://www.t } \\
\text { eses.usp.br/t } \\
\text { eses/disponi } \\
\text { veis/59/5913 } \\
\text { 7/tde- } \\
\text { 30072016- } \\
\text { 120110/ }\end{array}$ & $\begin{array}{l}\text { Alfabetização. } \\
\text { Brincar } \\
\text { Educação } \\
\text { Escola Lúdico }\end{array}$ & 2016 & $\begin{array}{l}\text { Concluiu-se que a brincadeira } \\
\text { é um forte recurso utilizado na } \\
\text { alfabetização de crianças, } \\
\text { contribuindo para o } \\
\text { desenvolvimento infantil } \\
\text { como um todo. }\end{array}$ \\
\hline 5 & $\begin{array}{l}\text { Andrade, } \\
\text { Juliano } \\
\text { Molinos } \\
\text { de }\end{array}$ & & $\begin{array}{c}\text { http://reposit } \\
\text { orio.ufsm.br/ } \\
\text { handle/1/190 } \\
88\end{array}$ & $\begin{array}{l}\text { Formação de } \\
\text { professor; jogos } \\
\text { didáticos; } \\
\text { atividades } \\
\text { lúdicas; } \\
\text { educação } \\
\text { profissional e } \\
\text { tecnológica. }\end{array}$ & 2019 & $\begin{array}{l}\text { Dessa forma verificou-se que } \\
\text { o processo de criação dos } \\
\text { jogos didáticos incentivou os } \\
\text { futuros professores, no seu } \\
\text { contexto profissional, ao } \\
\text { protagonismo na autoria e na } \\
\text { apropriação do material } \\
\text { didático que farão uso, além } \\
\text { de propiciar um ganho no } \\
\text { desenvolvimento dos saberes } \\
\text { docentes dos professores em } \\
\text { formação, visto que o } \\
\text { processo de criação dos jogos } \\
\text { exige um pensamento coletivo } \\
\text { para seu desenvolvimento. O } \\
\text { saber experiencial e o saber da } \\
\text { formação profissional foram } \\
\text { destacados através do primeiro } \\
\text { contato com as turmas, } \\
\text { enquanto o saber disciplinar e } \\
\text { o saber curricular tiveram seu } \\
\text { destaque através da } \\
\text { delimitação do tema e da } \\
\text { escolha das questões para a } \\
\text { criação do jogo didático } \\
\text { adequado para a série com a } \\
\text { qual cada um dos grupos } \\
\text { esteve inserido. }\end{array}$ \\
\hline
\end{tabular}




\begin{tabular}{|c|c|c|c|c|c|c|}
\hline 6 & $\begin{array}{l}\text { SILVA, } \\
\text { Suzana } \\
\text { Cínthia } \\
\text { Gomes } \\
\text { de } \\
\text { Medeiros }\end{array}$ & $\begin{array}{l}\text { A ludicidade } \\
\text { trabalhada } \\
\text { por } \\
\text { professores } \\
\text { de ciências } \\
\text { no ensino } \\
\text { fundamental }\end{array}$ & $\begin{array}{l}\text { http://www.t } \\
\text { ede2.ufrpe.b } \\
\text { r:8080/tede } 2 \\
\text { /handle/tede } \\
\text { 2/5346 }\end{array}$ & & 2016 & $\begin{array}{l}\text { Os resultados demonstraram } \\
\text { que, de modo geral, há } \\
\text { coerência entre o dizer e o } \\
\text { fazer docente, de forma que as } \\
\text { professoras valorizam a } \\
\text { utilização do lúdico como um } \\
\text { bom instrumento capaz de } \\
\text { auxiliar o processo de ensino- } \\
\text { aprendizagem de ciências, } \\
\text { indicando o lúdico não apenas } \\
\text { como um auxiliador nesse } \\
\text { processo, mas também como } \\
\text { algo que possibilita o } \\
\text { desenvolvimento humano em } \\
\text { várias dimensões. Por meio de } \\
\text { nossas observações, } \\
\text { constatamos o uso de algumas } \\
\text { estratégias lúdicas } \\
\text { interessantes para o contexto } \\
\text { dos anos iniciais, } \\
\text { evidenciando um aprendizado } \\
\text { lúdico de ciências. No entanto, } \\
\text { alguns planejamentos de aulas } \\
\text { se mostraram um tanto } \\
\text { inconsistentes devido a } \\
\text { carência de informações } \\
\text { acerca das atividades lúdicas a } \\
\text { serem desenvolvidas pelos } \\
\text { nossos sujeitos de pesquisa. } \\
\text { Como conclusão, } \\
\text { apresentamos algumas } \\
\text { sugestões, que possivelmente } \\
\text { poderão subsidiar futuros } \\
\text { estudos, que visem melhor } \\
\text { aprofundamento das } \\
\text { discussões que permeiam esse } \\
\text { estudo. }\end{array}$ \\
\hline 7 & $\begin{array}{c}\text { Dias, } \\
\text { Lilian } \\
\text { Santos } \\
\text { Morgado }\end{array}$ & $\begin{array}{l}\text { Da palavra } \\
\text { aos textos: o } \\
\text { lúdico e as } \\
\text { possibilidade } \\
\text { s práticas de } \\
\text { linguagens } \\
\text { na escola }\end{array}$ & $\begin{array}{c}\text { http://ri.ufs.b } \\
\text { r/jspui/handl } \\
\text { e/riufs/1251 } \\
6\end{array}$ & $\begin{array}{c}\text { Textos orais. } \\
\text { Textos escritos. } \\
\text { Jogo. }\end{array}$ & 2019 & $\begin{array}{l}\text { Este trabalho opta, portanto, } \\
\text { por investigar o desempenho } \\
\text { linguístico de alunos do } 90 \\
\text { ano do Ensino Fundamental, } \\
\text { de uma escola da rede pública } \\
\text { estadual da cidade de Barra } \\
\text { dos Coqueiros/SE, nas } \\
\text { práticas de oralidade e } \\
\text { produção escrita, através de } \\
\text { suporte sociocognitivo, a fim } \\
\text { de explorar a reverberaçâo que } \\
\text { esse olhar social pode trazer } \\
\text { para a relação } \\
\text { ensino/aprendizagem da } \\
\text { disciplina de Língua } \\
\text { Portuguesa, levando em conta } \\
\text { a interatividade, criatividade e } \\
\text { a relevância social da prática. } \\
\text { A pesquisa-ação apresenta } \\
\text { relatório acerca da utilização } \\
\text { do Produto/Jogo Didático de } \\
\text { produção de textos orais, } \\
\text { escritos e visuais, como }\end{array}$ \\
\hline
\end{tabular}




\begin{tabular}{|c|c|c|c|c|c|c|}
\hline & & & & & & $\begin{array}{l}\text { requisito para a conclusão do } \\
\text { curso, podendo ser aplicado e } \\
\text { replicado em outras séries e } \\
\text { em outras localidades. para o } \\
\text { lúdico na escola. }\end{array}$ \\
\hline 8 & $\begin{array}{l}\text { Bezerra, } \\
\text { Mário } \\
\text { Cezar } \\
\text { Augusto } \\
\text { de } \\
\text { Almeida }\end{array}$ & $\begin{array}{l}\text { Possibilidad } \\
\text { es lúdicas } \\
\text { com } \\
\text { tecnologias } \\
\text { digitais na } \\
\text { formação } \\
\text { docente: } \\
\text { uma } \\
\text { proposta de } \\
\text { espaço } \\
\text { maker no IF } \\
\\
\text { Sertão-PE } \\
\text { Campus } \\
\text { Petrolina. }\end{array}$ & $\begin{array}{l}\text { http://reposit } \\
\text { orio.ufba.br/ } \\
\text { ri/handle/ri/2 } \\
9780\end{array}$ & $\begin{array}{l}\text { Ludicidade - } \\
\text { Tecnologias - } \\
\text { Espaço Maker - } \\
\text { Hedonismo - } \\
\text { Formação } \\
\text { Docente }\end{array}$ & 2019 & $\begin{array}{l}\text { Propõe refletir sobre o Espaço } \\
\text { Maker como possibilidade de } \\
\text { lócus em que a ludicidade } \\
\text { integre a formação dos } \\
\text { professores, sugerindo o uso } \\
\text { lúdico das tecnologias digitais } \\
\text { e dos componentes, } \\
\text { ferramentas e máquinas } \\
\text { makers como forma } \\
\text { metodológica que diminua } \\
\text { tensões inerentes à práxis } \\
\text { pedagógica e empreste prazer } \\
\text { ao processo de ensino- } \\
\text { aprendizagem, na perspectiva } \\
\text { do hedonismo como valor e da } \\
\text { instantaneidade como } \\
\text { característica representativa } \\
\text { dos Séculos XX e XXI. }\end{array}$ \\
\hline 9 & $\begin{array}{l}\text { Pereira, } \\
\text { Uiliete } \\
\text { Marcia } \\
\text { Silva de } \\
\text { Mendonç } \\
\quad \text { a }\end{array}$ & $\begin{array}{l}\text { Metamorfos } \\
\text { es } \\
\text { formativas: } \\
\text { um estudo } \\
\text { sobre a } \\
\text { atividade } \\
\text { lúdica nos } \\
\text { anos iniciais } \\
\text { do ensino } \\
\text { fundamental }\end{array}$ & $\begin{array}{l}\text { https://reposi } \\
\text { torio.ufrn.br/ } \\
\text { jspui/handle/ } \\
\text { 123456789/2 } \\
6516\end{array}$ & $\begin{array}{l}\text { Brincadeira. } \\
\text { Necessidade de } \\
\text { formação. } \\
\text { Formação de } \\
\text { professores. } \\
\text { Ensino } \\
\text { Fundamental. }\end{array}$ & 2018 & $\begin{array}{l}\text { Nesse contexto, evidencia-se } \\
\text { que os resultados do trabalho } \\
\text { confirmam a tese de que a } \\
\text { formação contínua do } \\
\text { professor para desenvolver } \\
\text { uma prática pedagógica com } \\
\text { crianças dos anos iniciais do } \\
\text { ensino fundamental, tendo a } \\
\text { ludicidade como princípio } \\
\text { organizador, somente será } \\
\text { pertinente e efetiva se as } \\
\text { necessidades da formação } \\
\text { docente se constituírem como } \\
\text { a "base do processo } \\
\text { formativo". }\end{array}$ \\
\hline 10 & $\begin{array}{l}\text { Silva, } \\
\text { Janaina } \\
\text { Monteiro } \\
\text { da }\end{array}$ & $\begin{array}{c}\text { O lúdico no } \\
\text { processo de } \\
\text { ensino e } \\
\text { aprendizage } \\
\text { m: } \\
\text { concepções } \\
\text { e práticas } \\
\text { pedagógicas } \\
\text { de } \\
\text { professores } \\
\text { dos iniciais } \\
\text { do ensino } \\
\text { fundamental }\end{array}$ & $\begin{array}{c}\text { http://ri.ufmt } \\
\text {.br/handle/1/ } \\
1942\end{array}$ & $\begin{array}{l}\text { Ludicidade; } \\
\text { pratica } \\
\text { pedagógica; } \\
\text { docentes. }\end{array}$ & 2017 & $\begin{array}{l}\text { A A aprendizagem eficaz, na } \\
\text { perspectiva lúdica, só é } \\
\text { possível quando trabalhada de } \\
\text { forma planejada, organizada e } \\
\text { compromissada com os } \\
\text { conteúdos de ensino e quando } \\
\text { os objetivos são trabalhados } \\
\text { com fins educativos. O } \\
\text { trabalho pedagógico na } \\
\text { perspectiva lúdica reflete } \\
\text { positivamente na } \\
\text { aprendizagem dos conteúdos } \\
\text { de ensino quando pensada em } \\
\text { fins educativos e com } \\
\text { seriedade pelos professores. }\end{array}$ \\
\hline 11 & $\begin{array}{l}\text { Rios, } \\
\text { Luiz } \\
\text { Daniel } \\
\text { Alves }\end{array}$ & $\begin{array}{l}\text { Desenvolvi } \\
\text { mento de } \\
\text { jogos como } \\
\text { recurso } \\
\text { pedagógico }\end{array}$ & $\begin{array}{l}\text { http://www.r } \\
\text { epositorio.uf } \\
\text { c.br/handle/r } \\
\text { iufc/40444 }\end{array}$ & $\begin{array}{l}\text { Ludicidade; } \\
\text { Ensino de } \\
\text { Física; Jogos. }\end{array}$ & 2017 & $\begin{array}{c}\text { Com certeza, o jogo, a } \\
\text { brincadeira e o brinquedo } \\
\text { podem ser úteis viii para } \\
\text { estimular o desenvolvimento } \\
\text { do aluno. Para Santos (1997), } \\
\text { a ludicidade é uma } \\
\text { necessidade do ser humano em }\end{array}$ \\
\hline
\end{tabular}




\begin{tabular}{|c|c|c|c|c|c|c|}
\hline & & $\begin{array}{l}\text { no ensino de } \\
\text { física }\end{array}$ & & & & $\begin{array}{l}\text { qualquer idade e não pode ser } \\
\text { vista apenas como diversão. O } \\
\text { desenvolvimento do aspecto } \\
\text { lúdico facilita a aprendizagem, } \\
\text { o desenvolvimento pessoal, } \\
\text { social e cultural, colaborando } \\
\text { para uma boa saúde mental, } \\
\text { além de facilitar os processos } \\
\text { de socialização, comunicação, } \\
\text { expressão e construção do } \\
\text { conhecimento. Espera-se que } \\
\text { o estudo, aqui apresentado, e } \\
\text { os jogos desenvolvidos } \\
\text { possam contribuir para a } \\
\text { melhoria do desempenho, } \\
\text { tanto do corpo docente quanto } \\
\text { do discente, tornando assim, o } \\
\text { lúdico uma forma satisfatória } \\
\text { de adquirir conhecimento. }\end{array}$ \\
\hline 12 & $\begin{array}{l}\text { Costa, } \\
\text { Alexandr } \\
\text { e } \\
\text { Santiago } \\
\text { da }\end{array}$ & $\begin{array}{c}\text { Ludicidade, } \\
\text { estética e } \\
\text { formação em } \\
\text { contexto: as } \\
\text { implicações } \\
\text { de uma } \\
\text { proposta } \\
\text { formativa } \\
\text { ludo-estética } \\
\text { contextualiz } \\
\text { ada na } \\
\text { prática de } \\
\text { educadoras } \\
\text { infantis }\end{array}$ & $\begin{array}{l}\text { http://www.r } \\
\text { epositorio.uf } \\
\text { c.br/handle/r } \\
\text { iufc/28484 }\end{array}$ & $\begin{array}{l}\text { Estética Práticas } \\
\text { lúdicas } \\
\text { Formação do } \\
\text { educador } \\
\text { infantil }\end{array}$ & 2017 & $\begin{array}{l}\text { A pesquisa colaborativa } \\
\text { sugere que as práticas de } \\
\text { formação de professores da } \\
\text { educação infantil são } \\
\text { significativas se tomamos } \\
\text { como eixo vertebrador a } \\
\text { formação em contexto atrelada } \\
\text { à sua dimensão situada e que } \\
\text { apontam concretamente suas } \\
\text { necessidades e potencialidades } \\
\text { pessoais e institucionais. A } \\
\text { dimensão lúdica atrelada à } \\
\text { formação estética tem um } \\
\text { ganho formativo quando } \\
\text { alinhadas, fomentando uma } \\
\text { nova tessitura de saberes } \\
\text { culturais que transformam, } \\
\text { fortalecem e ampliam a } \\
\text { consciência estética dos } \\
\text { educadores, transfigurando, } \\
\text { assim, impactos e } \\
\text { transformações na sua práxis } \\
\text { pedagógica, no que tange às } \\
\text { linguagens visuais na } \\
\text { educação infantil. }\end{array}$ \\
\hline 13 & $\begin{array}{l}\text { SOARES } \\
\text {, L. C. }\end{array}$ & $\begin{array}{c}\text { ENUNCIAÇ } \\
\text { ÕES } \\
\text { DOCENTES } \\
\text { SOBRE O } \\
\text { BRINCAR } \\
\text { NOS } \\
\text { PROCESSO } \\
\text { S DE } \\
\text { FORMAÇÃ } \\
\text { O } \\
\text { CONTINUA } \\
\text { DA NA } \\
\text { EDUCAÇÃ }\end{array}$ & $\begin{array}{c}\text { http://reposit } \\
\text { orio.ufes.br/ } \\
\text { handle/10/86 } \\
04\end{array}$ & $\begin{array}{l}\text { Educação } \\
\text { Infantil } \\
\text { Formação } \\
\text { continuada } \\
\text { Brincadeira }\end{array}$ & 2017 & $\begin{array}{l}\text { Com a análise dos dados, os } \\
\text { resultados apontaram para a } \\
\text { importância de tematizar a } \\
\text { brincadeira nos processos } \\
\text { formativos, pois oportunizam } \\
\text { o compartilhamento de } \\
\text { saberes, ideias, relatos, } \\
\text { projetos e práticas que insiram } \\
\text { o brincar no trabalho } \\
\text { educativo com as crianças. } \\
\text { Assim, no desafio de suscitar } \\
\text { o desenvolvimento de } \\
\text { professores brincantes e, além } \\
\text { disso, de uma instituição } \\
\text { brincante, de modo que a } \\
\text { dimensão lúdica integre o }\end{array}$ \\
\hline
\end{tabular}




\begin{tabular}{|c|c|c|c|c|c|c|}
\hline & & $\begin{array}{c}\mathrm{O} \\
\text { INFANTIL }\end{array}$ & & & & $\begin{array}{c}\text { conjunto de ações que se } \\
\text { efetivam nesse espaço, acena- } \\
\text { se para a relevância de pensar } \\
\text { o brincar como ação que não } \\
\text { se limita às práticas } \\
\text { pedagógicas, mas questiona, } \\
\text { tensiona e mobiliza novas } \\
\text { práticas brincantes que } \\
\text { reconheçam a brincadeira } \\
\text { como atividade que permeia o } \\
\text { cotidiano da Educação } \\
\text { Infantil. }\end{array}$ \\
\hline 14 & $\begin{array}{l}\text { Pimentel, } \\
\text { Alessand } \\
\text { ra }\end{array}$ & $\begin{array}{l}\text { Jogo e } \\
\text { desenvolvim } \\
\text { ento } \\
\text { profissional: } \\
\text { análise de } \\
\text { uma } \\
\text { proposta de } \\
\text { formação } \\
\text { continuada } \\
\text { de } \\
\text { professores }\end{array}$ & $\begin{array}{c}\text { http://www.t } \\
\text { eses.usp.br/t } \\
\text { eses/disponi } \\
\text { veis/48/4813 } \\
4 / \text { tde- } \\
\text { 20012006- } \\
142239 /\end{array}$ & $\begin{array}{l}\text { aprendizagem } \\
\text { experiencial } \\
\text { desenvolviment } \\
\text { o profissional } \\
\text { educação lúdica } \\
\text { estudo de casos } \\
\text { formação } \\
\text { continuada de } \\
\text { professores jogo } \\
\text { educativo }\end{array}$ & 2019 & $\begin{array}{l}\text { Nesse sentido, sobressaem-se } \\
\text { as seguintes necessidades para } \\
\text { a área de formação de } \\
\text { professores, especialmente sob } \\
\text { a perspectiva da ludo- } \\
\text { educação: a) programas de } \\
\text { formação de médio e longo } \\
\text { prazo promoveriam a } \\
\text { consolidação de um sistema } \\
\text { conceitual complexo e } \\
\text { integrado ao desenvolvimento } \\
\text { profissional; b) a variação das } \\
\text { estratégias formativas, bem } \\
\text { como o apoio contínuo ao } \\
\text { educador - desde o } \\
\text { planejamento até a avaliação } \\
\text { das experiências - são } \\
\text { aspectos essenciais do } \\
\text { trabalho do formador; c) a } \\
\text { aprendizagem docente } \\
\text { depende de assegurar, no } \\
\text { contexto escolar, espaço } \\
\text { permanente de reflexão sobre } \\
\text { a ação pedagógica }\end{array}$ \\
\hline 15 & $\begin{array}{c}\text { Frenham, } \\
\text { Adriana } \\
\text { Maria } \\
\text { Biaggio }\end{array}$ & $\begin{array}{c}\text { Atividade } \\
\text { docente e } \\
\text { jogos } \\
\text { educativos } \\
\text { no processo } \\
\text { de ensino- } \\
\text { aprendizage } \\
\text { m: } \\
\text { significações } \\
\text { constituídas } \\
\text { por } \\
\text { professores } \\
\text { de Ensino } \\
\text { Fundamental } \\
\text { I de uma } \\
\text { rede pública } \\
\text { em } \\
\text { município da } \\
\text { Grande São } \\
\text { Paulo }\end{array}$ & $\begin{array}{l}\text { https://tede2. } \\
\text { pucsp.br/han } \\
\text { dle/handle/1 } \\
9276\end{array}$ & $\begin{array}{l}\text { Psicologia } \\
\text { sócio-histórica } \\
\text { Atividade } \\
\text { docente Jogos } \\
\text { educativos na } \\
\text { aprendizagem }\end{array}$ & 2016 & $\begin{array}{l}\text { Com base no resultado desses } \\
\text { procedimentos, foi possível } \\
\text { constatar que os sujeitos } \\
\text { compreendiam (ainda que não } \\
\text { plenamente) as possibilidades } \\
\text { lúdica e pedagógica da } \\
\text { estratégia dos jogos } \\
\text { educativos e dela faziam uso } \\
\text { na mediação de diferentes } \\
\text { conteúdos (conceituais, } \\
\text { procedimentais e atitudinais). } \\
\text { Além disso, consideravam que } \\
\text { esse recurso se apresentava } \\
\text { como um aliado do trabalho } \\
\text { docente e, também, como } \\
\text { facilitador da } \\
\text { aprendizagem.Foram } \\
\text { encontrados, por outro lado, } \\
\text { alguns aspectos que os } \\
\text { professores consideravam } \\
\text { como empecilhos ao emprego } \\
\text { de jogos educativos, indicando } \\
\text { a necessidade de se repensar a } \\
\text { configuracão das rotinas }\end{array}$ \\
\hline
\end{tabular}




\begin{tabular}{|c|c|c|c|c|c|c|}
\hline & & & & & & $\begin{array}{c}\text { escolares. Uma outra } \\
\text { indicação dada foi a } \\
\text { necessidade de se repensar a } \\
\text { natureza da formação contínua } \\
\text { disponibilizada aos docentes }\end{array}$ \\
\hline 16 & $\begin{array}{l}\text { Loro, } \\
\text { Alexandr } \\
\text { e Paul }\end{array}$ & $\begin{array}{l}\text { FORMAÇÃ } \\
\text { O DE } \\
\text { PROFESSO } \\
\text { RES E } \\
\text { REPRESEN } \\
\text { TAÇÕES } \\
\text { SOBRE O } \\
\text { BRINCAR: } \\
\text { Contribuiçõe } \\
\text { S das idéias } \\
\text { de Humberto } \\
\text { Maturana. }\end{array}$ & $\begin{array}{l}\text { http://reposit } \\
\text { orio.ufsm.br/ } \\
\text { handle/1/680 } \\
5\end{array}$ & $\begin{array}{c}\text { formação } \\
\text { docente; } \\
\text { saberes; brincar; } \\
\text { representações } \\
\text { sociais; } \\
\text { Humberto } \\
\text { Maturana. }\end{array}$ & 2016 & $\begin{array}{l}\text { Acredito que as professoras } \\
\text { possam proporcionar novos } \\
\text { espaços de convivência num } \\
\text { domínio de aceitação } \\
\text { recíproca com seus alunos, } \\
\text { produzindo uma dinâmica na } \\
\text { qual vão } \\
\text { mudando/transformando } \\
\text { juntos e em congruência. } \\
\text { Dessa maneira, os currículos } \\
\text { podem ser (re)organizados, no } \\
\text { sentido de sensibilizá-las em } \\
\text { sua formação, mobilizando a } \\
\text { emoção para uma formação } \\
\text { humana solidária, } \\
\text { fundamentada pelo amor. } \\
\text { Assim, o brincar poderia ser } \\
\text { percebido como um } \\
\text { fundamento do humano, como } \\
\text { defende Maturana e que foi } \\
\text { referência nessa pesquisa. }\end{array}$ \\
\hline 17 & $\begin{array}{l}\text { Gilson } \\
\text { Cruz } \\
\text { Junior }\end{array}$ & $\begin{array}{l}\text { Vivendo o } \\
\text { jogo ou } \\
\text { jogando a } \\
\text { vida? Notas } \\
\text { sobre jogos } \\
\text { (digitais) e } \\
\text { educação em } \\
\text { meio à } \\
\text { cultura } \\
\text { ludificada }\end{array}$ & $\begin{array}{l}\text { http://dx.doi. } \\
\text { org/10.1016/ } \\
\text { j.rbce.2017.0 } \\
\quad 2.012\end{array}$ & $\begin{array}{l}\text { Jogos digitais; } \\
\text { Educação; } \\
\text { Cultura; } \\
\text { Letramento }\end{array}$ & 2017 & $\begin{array}{l}\text { Mais do que manifestações da } \\
\text { cultura passíveis de expressão } \\
\text { por meio da linguagem, os } \\
\text { jogos representam uma } \\
\text { linguagem autônoma que traz } \\
\text { consigo implicações para o } \\
\text { modo como os indivíduos } \\
\text { assimilam, interpretam e } \\
\text { engendram significados dentro } \\
\text { e ao redor de seus contextos } \\
\text { lúdicos de interação. }\end{array}$ \\
\hline 18 & $\begin{array}{l}\text { Marcos } \\
\text { Nicolau } \\
\text { Santos da } \\
\text { Silv }\end{array}$ & $\begin{array}{l}\text { O território } \\
\text { camponês } \\
\text { como } \\
\text { dimensão } \\
\text { educativa: } \\
\text { desafios e } \\
\text { possibilidade } \\
\text { s da } \\
\text { Educação do } \\
\text { Campo em } \\
\text { Grajaú-MA }\end{array}$ & $\begin{array}{l}\text { http://hdl.ha } \\
\text { ndle.net/184 } \\
3 / 30475\end{array}$ & $\begin{array}{c}\text { Educação } \\
\text { Matemática; } \\
\text { Sujeito Lúdico; } \\
\text { Neoliberalismo }\end{array}$ & 2018 & $\begin{array}{l}\text { Em cada escola, as atividades } \\
\text { foram desenvolvidas em três } \\
\text { momentos com os estudantes: } \\
\text { o primeiro encontro realizou- } \\
\text { se a apresentação da proposta } \\
\text { de pesquisa e atividades } \\
\text { lúdicas para melhorar o } \\
\text { contato com os estudantes, } \\
\text { além de diagnóstico dos } \\
\text { problemas da escola e das } \\
\text { comunidades; o segundo } \\
\text { encontro desenvolveu-se um } \\
\text { mapa falado dos problemas } \\
\text { indicados no primeiro } \\
\text { encontro, utilizado como } \\
\text { instrumento metodológico do } \\
\text { Diagnóstico Rural } \\
\text { Participativo, bem como a } \\
\text { proposição de soluções para } \\
\text { os problemas elencados; no } \\
\text { terceiro encontro foram } \\
\text { realizadas entrevistas com os } \\
\text { gestores das escolas e com os }\end{array}$ \\
\hline
\end{tabular}




\begin{tabular}{|c|c|c|c|c|c|c|}
\hline & & & & & & $\begin{array}{l}\text { professores. Os resultados } \\
\text { evidenciaram que, na prática, } \\
\text { a Educação do Campo não } \\
\text { existe em Grajaú, pois as } \\
\text { escolas reproduzem o mesmo } \\
\text { modelo de educação da cidad }\end{array}$ \\
\hline 19 & $\begin{array}{l}\text { Menezes } \\
\text { Regiane } \\
\text { da Costa }\end{array}$ & $\begin{array}{l}\text { Práticas } \\
\text { lúdico- } \\
\text { reflexivas na } \\
\text { formação de } \\
\text { professores }\end{array}$ & $\begin{array}{l}\text { https://bibli } \\
\text { otecatede.un } \\
\text { inove.br/han } \\
\text { dle/tede/991 }\end{array}$ & $\begin{array}{l}\text { Lúdica reflexão } \\
\text { formação de } \\
\text { professores } \\
\text { prática docente }\end{array}$ & 2015 & $\begin{array}{l}\text { A pesquisa-ação colaborativa } \\
\text { revelou-se suficiente suporte } \\
\text { conceitual através do qual a } \\
\text { docente-mestranda descobriu- } \\
\text { se "do-discente" pesquisadora, } \\
\text { tornou mais própria sua } \\
\text { prática ao levantar e testar } \\
\text { hipóteses humanizando } \\
\text { relacionamentos } \\
\text { intencionalmente lúdico- } \\
\text { reflexivos. }\end{array}$ \\
\hline 20 & $\begin{array}{l}\text { Elvio } \\
\text { de } \\
\text { Carva } \\
\text { lho }\end{array}$ & $\begin{array}{c}\text { A SALA DE } \\
\text { AULA COMO } \\
\text { ESPAÇO DE } \\
\text { RESSIGNIFIC } \\
\text { AÇÃO DA } \\
\text { LUDICIDADE } \\
\text { E DA } \\
\text { AMOROSIDA } \\
\text { DE NA } \\
\text { FORMAÇÃO } \\
\text { DOCENTE }\end{array}$ & $\begin{array}{l}\text { https://www. } \\
\text { e- } \\
\text { publicacoes. } \\
\text { uerj.br/index } \\
\text {.php/revispsi } \\
\text { /article/view/ } \\
\text { 38811/27691 }\end{array}$ & $\begin{array}{c}\text { Formação } \\
\text { docente. Prática } \\
\text { pedagógica. } \\
\text { Ludicidade. } \\
\text { Amorosidade }\end{array}$ & 2014 & $\begin{array}{l}\text { Desse modo, concluímos que } \\
\text { o docente que vivenciar o } \\
\text { lúdico e a amorosidade, na sua } \\
\text { prática pedagógica, estará } \\
\text { reconhecendo a importância } \\
\text { da brincadeira e das relações } \\
\text { sócio-afetivas na formação } \\
\text { integral da criança. Ao passo } \\
\text { que, se ignorar tais evidências, } \\
\text { não se engajar às atividades } \\
\text { lúdicas e não se dispuser a } \\
\text { descontruir os corpos } \\
\text { formatados por uma formação } \\
\text { tradicional, terá maior } \\
\text { dificuldade em vivenciar o } \\
\text { lúdico assim como, um olhar } \\
\text { sensível para a prática } \\
\text { pedagógica lúdica dos seus } \\
\text { discentes, impossibilitando-os } \\
\text { de vivenciá-lo, nem só no } \\
\text { contexto escolar, mas também } \\
\text { nas relações sociais e familiar }\end{array}$ \\
\hline 21 & $\begin{array}{c}\text { GLEI } \\
\text { CIAN } \\
\text { E } \\
\text { ALBI } \\
\text { NO } \\
\text { CUN } \\
\text { HA }\end{array}$ & $\begin{array}{l}\text { O lúdico e sua } \\
\text { importância na } \\
\text { aprendizagem } \\
\text { da educação } \\
\text { infantil. }\end{array}$ & $\begin{array}{l}\text { https://cosmi } \\
\text { nha.jusbrasil } \\
\text {.com.br/artig } \\
\text { os/66201183 } \\
\text { 8/o-ludico-e- } \\
\text { sua- } \\
\text { importancia- } \\
\text { na- } \\
\text { aprendizage } \\
\text { m-da- } \\
\text { educacao- } \\
\text { infantil?ref= } \\
\text { serp }\end{array}$ & $\begin{array}{l}\text { Educação. } \\
\text { Lúdico. } \\
\text { Aprendizagem. } \\
\text { Infância. }\end{array}$ & 2019 & $\begin{array}{c}\text { Então podemos concluir que } \\
\text { por meio das brincadeiras os } \\
\text { professores podem observar e } \\
\text { constituir uma visão dos } \\
\text { processos de desenvolvimento } \\
\text { das crianças em conjunto e de } \\
\text { cada um em particular, } \\
\text { registrando suas capacidades } \\
\text { de uso de linguagens. É } \\
\text { preciso que o professor tenha } \\
\text { consciência que na brincadeira } \\
\text { as crianças criam e estabilizam } \\
\text { aquilo que sabem sobre as } \\
\text { mais diversas áreas e esferas } \\
\text { do conhecimento em uma } \\
\text { atividade espontânea e } \\
\text { imaginativa. }\end{array}$ \\
\hline 22 & $\begin{array}{l}\text { Tizuk } \\
\text { o } \\
\text { Morc } \\
\text { hidda }\end{array}$ & $\begin{array}{l}\text { Jogos, } \\
\text { brinquedose } \\
\text { brincadeiras do } \\
\text { Brasil } \\
\end{array}$ & $\begin{array}{c}\text { http://ref.scie } \\
\text { lo.org/pry67 } \\
8\end{array}$ & $\begin{array}{l}\text { jogo; } \\
\text { brincadeira; } \\
\text { criança -jovem - } \\
\text { adulto. } \\
\end{array}$ & 2014 & $\begin{array}{l}\text { A hibridez da cultura lúdica } \\
\text { dos tempos atuais revela a } \\
\text { aproximação das brincadeiras } \\
\text { da tradição de jovens de }\end{array}$ \\
\hline
\end{tabular}




\begin{tabular}{|c|c|c|c|c|c|c|}
\hline & $\begin{array}{l}\text { Kishi } \\
\text { moto }\end{array}$ & & & & & $\begin{array}{c}\text { diferentes países, } \\
\text { evidenciando ao mesmo } \\
\text { tempo a tradição e a mudança, } \\
\text { o protagonismo dos } \\
\text { brincantes, com o colorido da } \\
\text { localidade e a identidade dos } \\
\text { sujeitos, permanecendo sem } \\
\text { mudança a estrutura do jogo. }\end{array}$ \\
\hline 23 & $\begin{array}{l}\text { Asqui } \\
\text { no.An } \\
\text { dreia } \\
\text { Bugui }\end{array}$ & $\begin{array}{l}\text { Educação } \\
\text { infantil: as } \\
\text { práticas } \\
\text { pedagógicas } \\
\text { lúdicas de } \\
\text { alfabetização e } \\
\text { letramento }\end{array}$ & $\begin{array}{l}\text { http://bibliot } \\
\text { ecatede.unin } \\
\text { ove.br/handl } \\
\text { e/tede/2001 }\end{array}$ & $\begin{array}{l}\text { letramento/alfab } \\
\text { etização } \\
\text { educação } \\
\text { infantil práticas } \\
\text { pedagógicas } \\
\text { lúdicas }\end{array}$ & 2019 & $\begin{array}{l}\text { Esta pesquisa caminhou na } \\
\text { direção de que não é mesmo } \\
\text { cabível, na Educação Infantil, } \\
\text { que se coloque como objetivo } \\
\text { a alfabetização das crianças. } \\
\text { Isso, porém, não significa que } \\
\text { o processo de aproximação } \\
\text { progressiva à leitura e à } \\
\text { escrita, não possa ser iniciado } \\
\text { neste momento da vida } \\
\text { infantil. A essa aproximação } \\
\text { progressiva é que se } \\
\text { denomina, aqui, de letramento. } \\
\text { Ainda mais se essa } \\
\text { aproximação progressiva se dá } \\
\text { envolvida na ludicidade } \\
\text { própria desse momento da } \\
\text { vida humana. }\end{array}$ \\
\hline 24 & $\begin{array}{l}\text { Vasco } \\
\text { ncello } \\
\text { s, } \\
\text { Talita } \\
\text { Silva } \\
\text { Perus } \\
\text { si }\end{array}$ & $\begin{array}{c}\text { Jogos de } \\
\text { tabuleiro: } \\
\text { recurso lúdico } \\
\text { na apropriação } \\
\text { de leitura e } \\
\text { escrita de } \\
\text { crianças em } \\
\text { situação de } \\
\text { vulnerabilidade }\end{array}$ & $\begin{array}{l}\text { https://reposi } \\
\text { torio.ufscar. } \\
\text { br/handle/ufs } \\
\text { car/11351 }\end{array}$ & $\begin{array}{c}\text { Educação } \\
\text { Especial. Jogos } \\
\text { de tabuleiro. } \\
\text { Leitura e escrita. } \\
\text { Vulnerabilidade } \\
\text { social. }\end{array}$ & 2019 & $\begin{array}{l}\text { Os resultados mostraram um } \\
\text { ganho de habilidades ao } \\
\text { processo de aquisição de } \\
\text { leitura e escrita, visto que a } \\
\text { aplicação das avaliações } \\
\text { demostrou que todas as } \\
\text { meninas avançaram na } \\
\text { apropriação de habilidades de } \\
\text { escrita possivelmente por } \\
\text { influência do jogo. Logo, é } \\
\text { possível indicar que o jogo de } \\
\text { tabuleiro pode ser considerado } \\
\text { um recurso facilitador no } \\
\text { processo de apropriação das } \\
\text { habilidades relacionadas à } \\
\text { leitura e à escrita de crianças } \\
\text { em situação de } \\
\text { vulnerabilidade social. } \\
\text { Destaca-se, ainda, a } \\
\text { importância de novos estudos } \\
\text { que ofereçam diferentes } \\
\text { mecanismos de ensino das } \\
\text { habilidades de leitura e escrita, } \\
\text { com foco nas potencialidades } \\
\text { e saberes do aprendiz, para } \\
\text { que, de fato, ele se torne ativo } \\
\text { no processo de ensino e } \\
\text { aprendizagem. }\end{array}$ \\
\hline 25 & $\begin{array}{l}\text { Cruz, } \\
\text { Dioze } \\
\text { Hofm } \\
\text { am da }\end{array}$ & $\begin{array}{l}\text { Práticas } \\
\text { docentes no } \\
\text { ensino } \\
\text { fundamental: as } \\
\text { contribuições da } \\
\text { corporeidade e } \\
\end{array}$ & $\begin{array}{c}\text { https://reposi } \\
\text { torio.ucs.br/ } \\
11338 / 5531\end{array}$ & $\begin{array}{c}\text { Jogo; } \\
\text { Brincadeira; } \\
\text { Infância; Prática } \\
\text { Pedagógica; } \\
\text { Aprendizagem }\end{array}$ & 2019 & $\begin{array}{l}\text { Os resultados permitem } \\
\text { identificar que vários dos } \\
\text { professores entrevistados } \\
\text { compreendem o conceito de } \\
\text { corporeidade, deixando a } \\
\text { dicotomia de lado e }\end{array}$ \\
\hline
\end{tabular}




\begin{tabular}{|c|c|c|c|c|c|c|}
\hline & & $\begin{array}{c}\text { suas relações } \\
\text { com a } \\
\text { ludicidade }\end{array}$ & & & & $\begin{array}{l}\text { articulando corpo e mente na } \\
\text { busca de uma formação } \\
\text { integral do ser humano. Em } \\
\text { contrapartida, nota-se que há } \\
\text { alguns docentes que ainda não } \\
\text { construíram essa } \\
\text { compreensão, que acabam não } \\
\text { realizando a articulação } \\
\text { necessária, o que pode resultar } \\
\text { em prejuízos para as crianças. } \\
\text { Entende-se que esse déficit } \\
\text { pode estar vinculado à falta de } \\
\text { vivência dos professores com } \\
\text { a corporeidade em suas } \\
\text { formações. No momento em } \\
\text { que os docentes buscam } \\
\text { estratégias para abordar a } \\
\text { corporeidade, o lúdico se } \\
\text { evidencia como uma forma } \\
\text { efetiva, encontrando } \\
\text { potencialidades e limitações } \\
\text { na sua utilização, podendo ser } \\
\text { abordado pelas diferentes } \\
\text { formas de expressões. } \\
\text { Considera-se, portanto, que } \\
\text { explorar a corporeidade é } \\
\text { desafiador, um professor } \\
\text { aberto a mudanças, em } \\
\text { constante aprendizado pode } \\
\text { contribuir com a } \\
\text { aprendizagem dos seus alunos } \\
\text { em sala de aula, propiciando, } \\
\text { dessa forma, uma educação } \\
\text { integral e transformadora. }\end{array}$ \\
\hline 27 & $\begin{array}{l}\text { MOD } \\
\text { ESTO } \\
\text {, Ester }\end{array}$ & $\begin{array}{c}\text { Docentes em } \\
\text { serviço: sujeitos } \\
\text { e subjetividades } \\
\text { na formação de } \\
\text { professores }\end{array}$ & $\begin{array}{l}\text { http://bdtd.uf } \\
\text { tm.edu.br/ha } \\
\text { ndle/tede/96 } \\
9\end{array}$ & $\begin{array}{l}\text { Subjetividade. } \\
\text { Ensino superior. } \\
\text { Formação de } \\
\text { professores. } \\
\text { Teoria da } \\
\text { atividade. }\end{array}$ & 2016 & $\begin{array}{l}\text { A Escolha da profissão: que } \\
\text { estão contidas nas falas dos } \\
\text { professores o que eles } \\
\text { acreditam ser capazes de } \\
\text { fazer, ou mais } \\
\text { especificadamente o que ela é } \\
\text { induzida a fazer, pois deve } \\
\text { realizar esta escolha para } \\
\text { formalizar sua profissão; } \\
\text { Percurso de Formação: a } \\
\text { trajetória de vida do professor } \\
\text { universitário direcionando } \\
\text { para a sua formação e } \\
\text { realização da prática atual; O } \\
\text { que é Ser professor: } \\
\text { discutimos um ser que está } \\
\text { sempre em construção, } \\
\text { polivalente e transformador; } \\
\text { Quem sou Eu: parte da } \\
\text { complexidade do ser, como o } \\
\text { entrevistado se reconhece e o } \\
\text { sujeito se vê como pessoa e } \\
\text { profissional; Como vejo meu } \\
\text { trabalho: ação profissional, o } \\
\text { reconhecimento, a } \\
\text { autorreflexão sobre o que está }\end{array}$ \\
\hline
\end{tabular}




\begin{tabular}{|l|l|l|l|c|}
\hline & & & & \\
& & & $\begin{array}{c}\text { sendo feito durante a sua } \\
\text { prática, e a formação } \\
\text { profissional; Eu e à Docência: } \\
\text { reflete todas as categorias } \\
\text { anteriores, como sua } \\
\text { constituição pessoal e } \\
\text { profissional. O trabalho } \\
\text { realizado acrescenta } \\
\text { conhecimento para um olhar } \\
\text { diferenciado para a formação } \\
\text { de professores universitários, } \\
\text { principalmente àqueles que se } \\
\text { tornam profissionais } \\
\text { constituindo-se professor. }\end{array}$ \\
\hline
\end{tabular}


Considerando a análise crítica dos artigos selecionados, a categorização relacionada à pergunta norteadora do presente estudo propiciou a discussão acerca do (i) Ensino aprendizagem e formação inicial docente: Aspectos históricos e de inovação; (ii) Adoção, percepção e relevância do método lúdico na formação docente.

A discussão centrada nessa categorização será abordada através de eixos temáticos correlacionados, como segue:

\section{Ensino aprendizagem e formação inicial docente: aspectos históricos e de inovação}

Loro (2016) comenta que hoje, mais do que nunca, o professor necessita atualizar-se constantemente para atender às necessidades educacionais escolares. Vivemos numa sociedade planetarizada, onde os profissionais necessitam ser multifuncionais e competentes. Alarcão (2001) explicita que a função dos docentes exige consciência de que sua formação nunca está finda, pelo contrário, encontra-se num constante vir a ser, primando pela qualidade de seu ofício e pela sua flexibilização diante de tantas mudanças.

Não faz muito tempo que qualquer profissional poderia acreditar que munido de um diploma de graduação, estaria capacitado para o resto da sua vida profissional, mas não é bem assim, pois a formação de um professor se dá a longo prazo não se finalizacomo diploma na mao.

Loro (2016) diz que a formação inicial parece não ser mais que o primeiro passo para a formação docente contínua. Muitos profissionais acabam reproduzindo na escola o que eles aprenderam com seus professores na época de academia. Outros, porém, buscam se aperfeiçoar/qualificar constantemente para melhorar a qualidade da educação através de aquisição de livros, participação em grupos de estudos, palestras, oficinas, congressos e cursos de pós-graduação.

A preocupação com a formação do professor tem instigado diversos debates, e sido tema de reflexões em pesquisas de graduação e especialização, pós-graduação (lato sensu), mestrado e doutorado - (stricto sensu). No mundo globalizado em que este profissional está inserido, torna-se de fundamental importância que ele procure ampliar sua formação, na procura de tornar-se um profissional com competência técnica e sociopolítica, mediando o ensino, tendo consciência de suas funções, tornando-se assim, um profissional mais seguro, tendo melhores condições de auxiliar na construção da identidade. 
Estar dentro do processo educacional, com a tarefa de educar crianças, não é simples; é necessário preparar-se. Os professores não nascem com a capacidade inata de educar, é preciso desenvolvê-la, praticar e refletir para conseguir alcançar o objetivo. Nesse sentido, (CRUZ,2019) utiliza a fala Gatti (1997) onde ele analisa que "A universidade tem posto sistematicamente em segundo plano a formação de professores". Parece que alguma crença do tipo "quem sabe, sabe ensinar" ou "o professor nasce feito" ainda predominam em nosso meio, embora a realidade esteja a toda hora contraditando essas crenças"

O processo de formação de professores requer mudanças profundas na estratégia pedagógica devido à atual condição que envolve, em sua complexidade, as múltiplas relações entre a práxis escolar, o processo ensinoaprendizagem, a relação professorinstituição formadora e professor-aluno no contexto escolar.

Loro (2016) ainda menciona que ao considerar as demais formações (informais), a exemplo dos processos de autoformação, investimento educativo das situações profissionais e articulação com projetos educativos na escola, estaremos valorizando não apenas a sua formação, mas também reforçando a autonomia da própria escola. Por isso, a Formação Contínua não se reduz a um simples aperfeiçoamento, mas a uma possibilidade de reforma educativa inovadora, que visa resolver os problemas das instituições escolares. É nessa perspectiva de Formação Contínua que cortesão (1991) deposita uma esperança de proposta de trabalho em "investigação-ação". Ao aproximar a teoria com a prática, diluindo as barreiras existentes, haverá possibilidades de explorar a interação de diversas situações vistas tradicionalmente como opostas ou excludentes.

O debate dos pesquisadores sobre a temática da formação de professores acontece, dentre outros fatores, em virtude das relações em que se insere a problemática, sobretudo, em face do contexto social vigente. Este é influenciado pelas forças neoliberais de políticas educacionais que não atendem às necessidades básicas da educação para que a construção do conhecimento seja bem sucedida no seio da escola.

A LDB dispõe, no título VI art. 62, p. 59:

A formação de docentes para atuar na educação básica far-se-á em nível superior, em curso de licenciatura, em universidades e institutos superiores de educação, como formação mínima 
para o exercício do magistério na educação infantil e nas quatro primeiras séries do ensino fundamental, a oferecida em nível médio, na modalidade normal.

Duas razões contribuem para a construção desse consenso: o contexto econômico e cultural, que impõe a revisão dos conteúdos do ensino; e a LDB, que atua como fator de coesão. $\mathrm{Na}$ medida em que as principais respostas para essa revisão foram contempladas na lei, os vários âmbitos ou instâncias de sua regulamentação e execução estão empenhados em colocá-la em prática.

\section{A educação escolar é uma política pública endereçada à constituição da cidadania.}

Luckesi (2014) apud (Pereira, 2017) aborda a questão da formação do educador comprometido com a ludicidade. Partindo do princípio de que deve haver um compromisso do educador com a ludicidade ou com a promoção de atividades em que seja possível experimentar o estado de inteireza.

É difícil promover atividades pedagógicas lúdicas se o próprio educador não tiver a experiência de viver a plenitude de experiência em situações da sua formação e da sua vida pessoal. Essa prática, ao longo do exercício profissional, pode constituir uma base de saberes capaz de potencializar a promoção de atividades lúdicas na prática pedagógica, conformando uma expertise docente que contribua, tanto para o seu desenvolvimento profissional, quanto para o aumento da criação e realização de atividades lúdicas em sala de aula.

Para (Pereira, 2017) a ludicidade vem conquistando espaço na universidade, especialmente, na formação de docentes. No entanto, mesmo com o avanço de pesquisas sobre esse tema a autora compreende, também, que há poucas referências bibliográficas que abordam essa temática, por existir ainda muitas lacunas de conhecimento acerca na formação universitária.

Convém ressaltar que é de acordo com a Base Nacional Comum Curricular (BNCC) portanto, faz-se necessário que os espaços sejam urgentemente ressignificados, a fim de garantir que as crianças possam brincar, investigar, correr, pesquisar, pois quanto mais lúdico, cuidadoso, acolhedor, propositivo e desafiador for o ambiente educacional maior será o desenvolvimento da criança, a aposta é que a ludicidade deve ser o ponto de partida dos currículos da Educação Infantil.

Brincando e jogando, a criança reproduz as suas vivências, 
transformando o real de acordo com os seus desejos e interesses. Por isso, podese dizer que através do brinquedo e do jogo, a criança expressa, assimila e constrói a sua realidade. É o reconhecimento do valor inerente do prazer de pertencer a esse enorme tabuleiro em que ganhamos, perdemos, jogamos e aprendemos, sempre.

Fantacholi (2016) diz que dentro do contexto educacional a oportunidade do brincar assumiu características próprias, hoje podemos afirmar, com segurança, que a brincadeira é um agente de mudança do ponto de vista educacional, e por acreditar nesta afirmação, consideramos que o desenvolvimento da criança acontece através do lúdico, ela precisa brincar para crescer e desenvolver integralmente.

Afirma também que a Escola deve ser local de aprendizados diversos, onde seja possível desenvolver potencialidades dos múltiplos aspectos do desenvolvimento humano.Que a brincadeira seja vista e tratada com o respeito e a consideração que lhe é devida. E ocupe lugar de destaque, de alegria, de riso, movimento para reinventar experiências como divertir, distrair,se relacionar com os outros, tais como: cantar, imaginar, enfim atividades carregadas de possibilidades e significados favoráveis à inter- relação pessoal ou grupal.

Para Bizerra (2017) a ludicidade é uma proposta que permite que tanto o educador quanto o educando, caminhem pelo sensível de cada um, pelo perceptível, sentimentos e sensações, mostrando uma forma mais autêntica de ensinar e de interagir com o mundo e com o outro, com o artístico e suas expressões, o corpo e suas diferentes linguagens, é um formato de aprendizagem que inclui todas as formas de comunicação e ao mesmo tempo, é um convite para apreciar o belo, sentir e a criar, com liberdade e criatividade, construindo práticas mais integrativas e significativas.

\section{Adoção, percepção e relevância do método lúdico na formação docente}

A infância não é apenas uma passagem cronológica na vida da criança; ao contrário é uma condição histórica, social e cultural. É um momento de apropriação de imagens e de representações diversas que transitam por diferentes canais de comunicação, por isso, não é apenas uma etapa, uma fase numerável ou quantificável da vida humana. Diante disso, pensar o trabalho pedagógico que incorpora o lúdico como proposta de conteúdo, torna-se de grande relevância no campo educacional, já que 
por meio dos jogos, brincadeiras, dramatizações, contação de histórias, teatro, entre outros, a criança aprende sobre o mundo que a cerca e adquire novos saberes na educação infantil.

Rios (2017) diz que ouso dos jogos na aprendizagem é algo muito importante, pois o próprio professor, em relação ao que quer ensinar, muda sua metodologia para melhor, porque o lúdico favorece este comportamento.

O autor também afirma que ele passa a ser um observador, um questionador, incentivador da aprendizagem e do processo de construção do saber pelo aluno. Quando o professor lança atividades lúdicas desafiadoras, os alunos se questionam uns com os outros e apresentam soluções para os problemas que surgem, tudo isso porque usam o lúdico como suporte para esse desafio, pois, às vezes, as situações forçam a reflexão e eles aprendem a se socializar, o que é muito importante, tanto para quem aprende como para quem ensina.

O jogo, para o aluno, é um desafio; em cada jogada, uma reflexão e em cada perda ou vitória, um aprendizado (Moura, 1994 apud Rios 2017). É claro que, quando se usa jogo na sala de aula, o barulho é inevitável, pois só através de discussões é possível chegar-se a resultados convincentes.
Assim, se o aluno conseguir aprender, não há nada de errado reservar alguns minutos da aula para essa atividade, pois, ao discutir regras, ao competir, várias coisas estão acontecendo em sua vida: Interação, direcionamento de regras, discussões sobre o que é certo ou errado, tira dúvidas.

É preciso encarar esse "barulho dos jogos" de uma forma construtiva; se assim não for procedido, não há motivação para o jogo. Ao se falar em motivação, nota-se que ela é uma parceira para a aprendizagem. A escola, com todas as suas contradições e limites, ocupa um espaço privilegiado na vida dos educandos e influencia intencionalmente, ou não, na construção de suas identidades e projetos de vida. Guimarães e colaboradores (2002 apud Rios) apontaram que.

Apesar de limitada por um programa, um conteúdo, um tempo pré determinado, normas internas e pela infraestrutura da instituição, é a interação entre o professor e o aluno que vai dirigir o processo educativo. Conforme a maneira pela qual está interação se dá, a aprendizagem do aluno pode ser mais ou menos facilitada e orientada para outra direção.

O contrato que liga o professor ao aluno é composto de uma reciprocidade essencial, que é o princípio e a base de 
uma colaboração. A relação professoraluno necessita que o educador, ao facilitar o conhecimento, apresente o conteúdo, e haja atuação do aluno ao recebê-lo, que facilite as formas de avaliação e que a reação dos pais, frente a essa nova postura da escola, seja de plena aceitação.

A aprendizagem é o resultado da complementaridade aprendente ensinante - conteúdo - eu - mundo. Essa relação é indispensável, pois a escola tem um papel importante na formação do indivíduo e, por ser responsável significativamente pelo processo de aprendizagem do ser humano e por cumprir o papel de mediadora, pensouse, inicialmente, que a atividade relação professor-aluno possa servir como reeducadora, fonte de experiência para a educação de problemas educacionais.

É também muito importante que o professor demonstre que gosta do que faz, seu semblante revele ser a sala de aula um lugar em que ele se sinta bem, para isto, entretanto, é crucial que a escola de "ser professor" esteja marcada pela paixão de formar. Este perfil de professor é formado pelos alunos como um líder, um referencial consequentemente. Sua palavra também é formada como a de alguém responsável digna de ser ouvida.
Um professor sensibilizado possibilita espaço para que haja a circulação da palavra, apostando na possibilidade discursiva de seus alunos. De nada adianta falar sobre organização, responsabilidade, ética autonomia, se na prática não houver um relacionamento saudável entre professor e aluno.

É muito importante utilizar os jogos no processo educacional pelo fato deles, geralmente, afetarem a motivação, as funções cognitivas e a curiosidade do aprendiz, pois permitem a experimentação e a exploração pelo usuário. Quando bem trabalhado, a potencialidade dos jogos é animadora. Um dos grandes perigos na elaboração de jogos é apresentar para os jogadores uma coleção de enigmas sem nenhuma ligação, tornando o jogo desinteressante.

Por sua necessidade intrínseca de unir diversão a aprendizado, os jogos constituem um desafio bastante complexo no que diz respeito à aceitação final do usuário. Projetistas e desenvolvedores de jogos não educativos estão, por sua vez, focados em um produto final cujo sucesso é o número de vendas.

Equipes envolvidas na elaboração de jogos educativos deparam-se com um obstáculo a mais: fazer com que o tópico de aprendizagem seja assimilado com sucesso pelo 
jogador, despertando o interesse pelo conteúdo. Entretanto, uma bem-sucedida assimilação do conteúdo educacional pode ir de encontro a requisitos básicos de jogos, como diversão e jogabilidade. Em outras palavras, o desenvolvimento de jogos educativos requer um cuidado extra: encontrar um equilíbrio coerente entre diversão e aprendizado de modo a evitar que um prejudique o outro. Rios (2017)

O uso dos jogos na aprendizagem é algo muito importante, pois o próprio professor, em relação ao que quer ensinar, muda sua metodologia para melhor, porque o lúdico favorece este comportamento.

Ele passa a ser um observador, um questionador, incentivador da aprendizagem e do processo de construção do saber pelo aluno. Quando o professor lança atividades lúdicas desafiadoras, os alunos se questionam uns com os outros e apresentam soluções para os problemas que surgem, tudo isso porque usam o lúdico como suporte para esse desafio, pois, às vezes, as situações forçam a reflexão e eles aprendem a se socializar, o que é muito importante, tanto para quem aprende como para quem ensina.

O professor deve, portanto, proporcionar situações importantes dentro da vivência em sala de aula. É neste sentido que o RCNEI (1998), sustenta que: Educar significa, portanto, propiciar situações de cuidados, brincadeiras e aprendizagens orientadas de forma integrada e que possam contribuir para o desenvolvimento das capacidades infantis de relação interpessoal, de ser e estar com os outros em uma atitude básica de aceitação, respeito e confiança, e o acesso, pelas crianças, aos conhecimentos mais amplos da realidade social e cultural (BRASIL, 1998, p. 23).

\section{CONCLUSÃO}

O brincar vem sendo entendido pelas professoras como um recurso, um método ou uma estratégia pedagógica para se obter um determinado fim. O brincar seria um meio e não um fim em si mesmo. Nesse sentido, o brincar tem a função de disciplinar e orientar os alunos para a aprendizagem de alguma coisa, a exemplo do letramento, socialização, integração ou recreação. Ainda, o brincar teria a função de amenizar a dureza na aprendizagem dos conteúdos ou ocupar o tempo de forma "saudável".

Diante de todas as informações contidas nesse estudo pode-se concluir que é bastante importante mencionar que as atividades lúdicas em sala de aula, podem ser consideradas contribuições 
positivas para professores e crianças da educação infantil

As atividades lúdicas são importantes na educação, portanto, os jogos, brinquedos e brincadeiras devem estar presentes nas ações pedagógicas das educadoras. Na realidade observada, mesmo que algumas atividades deixem a desejar, as mesmas, vem contribuindo no dia a dia.

Nesse sentido, o lúdico deve estar presente no processo de ensinoaprendizagem, contribuindo na metodologia de ensino, sendo considerado um importante fator neste processo, que vem acarretada de uma educação flexível, que norteiam aspectos e características que serão importantes para o aprendizado e para inserção no meio social.

Na sala de aula, o lúdico deve ser encarado como algo sério e de cunho pedagógico, fazendo-se assim necessário o educador conhecer as diversas práticas lúdicas, proporcionando aos educandos um ensino que valorize e aprecie seus gostos, aprendendo-se, assim, a controlar um universo simbólico particularmente vivido por cada um; procurando despertar suas inteligências e habilidades, desapegando-se de velhas metodologias de ensino que já estão em alguns casos ultrapassadas, dando lugar uma visão centrada em práticas realmente competentes.

\section{REFERENCIAS}

ALARCÃO, I. (org.). Escola reflexiva e nova racionalidade. Porto Alegre: Artmed, 2001.

BRASIL. Constituição (1988). Constituição da República Federativa do Brasil: promulgada em 5 de outubro de 1988: atualizada até a Emenda Constitucional n. 20, de 15-12-1998. 21. ed. São Paulo: Saraiva, 1999.

BRASIL. Secretaria de Educação Fundamental. Parâmetros Curriculares Nacionais: Educação Física/Secretaria de Educação Fundamental. Brasília: MEC/SEF, 1997. BRASIL. Lei Federal no. 8.069/90. Estatuto da criança e do adolescente. Santa Maria, RS: Pallotti, 2001.

BRASIL. Ministério da Educação e Cultura. Lei de Diretrizes e Bases da Educação Nacional. Lei n 9.394/96, publicada no DOU de 23/12/1996, Seção I, p. 27839. São Paulo: Imprensa Oficial do Estado, 1996. Ministério da Educação e do

Desporto. Secretaria da Educação Fundamental. Referencial curricular nacional para educação infantil. Brasília: MEC/SEF, 1998. v. I, II, III. Ministério da Educação e Cultura. Parâmetros Curriculares Nacionais. Brasília: 1997. 
GATTI, Bernadete. Questões em torno de qualidade da formação de professores. In Formação de professores e carreira. São Paulo: Cortez, 1997.

GUIMARÃES, G. TV e escola: discursos em confronto. 3 ed. São Paulo: Cortez, 2002.

LOPES, Mary Stela Sakamoto. O direito de aprendizagem e do brincar nos anos iniciais do ensino fundamental: formação lúdica docente (2018).

http://hdl.handle.net/11449/153507. Acesso em 20/09/2020

LORO, Alexandre Paul. FORMAÇÃ̃ DE PROFESSORES E REPRESENTAÇÕES SOBRE O BRINCAR: Contribuições das ideias de Humberto Maturana. 2016.

http://repositorio.ufsm.br/handle/1/6805. Acesso em 19/09/2020.

LUCKESI, Cipriano Carlos.

Ludopedagogia partilhando uma experiência e uma proposta, In:

LUCKESI, Cipriano Carlos. (Org.), Ludopedagogia - Ensaios 01, Salvaor: GEPEL/FACED/UFBA, 2000. p. 119-131.

LUCKESI, Cipriano Carlos. Ludicidade e experiências lúdicas: uma abordagem a partir da experiência interna. In: PORTO, Bernadete de Souza (Org.). Educação e Ludicidade - Ensaios 02, GEPEL/FACED/ UFBA, 2002, p. 22-60. Disponível em:
LUCKESI, Cipriano Carlos Estados de consciência e atividades lúdicas, in Bernadete de Souza Porto (Org.), Educação e Ludicidade - Ensaios 3, GEPEL/FACED/UFBA, 2004, pág. 11 a 20.

MOURA, M. O. A séria busca no jogo: do Lúdico na Matemática. In: A Educação Matemática em Revista. São Paulo: SBEMSP, 1994. 17-24 p.

PEREIRA, Fernanda Almeida. Ludicidade na constituição da profissionalidade de docentes de uma creche universitária: desafios e possibilidades (2018). http://repositorio.ufba.br/ri/handle/ri/23985 Acesso em 25/09/2020 RIOS, Luiz Daniel Alves. Desenvolvimento de jogos como recurso pedagógico no ensino de física. http://www.repositorio.ufc.br/handle/riufc/4 0444. Acesso em 23/09/2020.

SILVEIRA, Matheus Rego. Concepções e práticas docentes sobre o brincar em sala de aula no primeiro ano do Ensino Fundamental. (2016). http://www.teses.usp.br/teses/disponiveis/ 59/59137/tde-30072016-120110/.Acesso em 20/09/2020.

SILVA, Janaina Monteiro da. O lúdico no processo de ensino e aprendizagem: concepções e práticas pedagógicas de professores dos iniciais do ensino 
fundamental. 2017. Acesso em 19/09/2020. 